\title{
Apparent Emotional Expression Explains the Effects of Head Posture on Perceived Trustworthiness and Dominance, but a Measure of Facial Width Does Not
}

\author{
Dongyu Zhang ${ }^{\mathrm{a}, \mathrm{b}}$, Hongfei Lin ${ }^{\mathrm{a}}$ and David I Perrett $\mathrm{t}^{\mathrm{b}}$ \\ ${ }^{a}$ Dalian University of Technology, Dalian, Liaoning 116024, China; ${ }^{b}$ University of St Andrews, St \\ Mary's Quad, St Andrews, Fife, KY16 9JP, Scotland, United Kingdom
}

\author{
ARTICLE HISTORY \\ Compiled November 24, 2019
}

\begin{abstract}
Interpreting the personality and the disposition of people is important for social interaction. Both emotional expression and facial width are known to affect personality perception. Moreover, both the apparent emotional expression and the apparent width-to-height ratio of the face change with head tilt. We investigated how head tilt affects judgements of trustworthiness and dominance and whether such trait judgements reflect apparent emotion or facial width. Sixty-seven participants rated the dominance, emotion and trustworthiness of 24 faces posing with different head tilts while maintaining eye gaze at the camera. Both the 30 degrees up and 20 degrees down head postures were perceived as less trustworthy and more dominant (less submissive) than the head-level posture. Change in perceived trustworthiness and submissiveness with head tilt correlated with change in apparent emotional positivity but not change in facial width. Hence, our analysis suggests that apparent emotional expression provides a better explanation of perceived trustworthiness and dominance compared with cues to facial structure.
\end{abstract}

\section{KEYWORDS}

head posture; trustworthiness; dominance; emotional expression; facial widthto-height ratio

\section{Introduction}

People rapidly make trait judgements from facial clues and reach a consensus on their judgement (Krumhuber et al., 2007; Todorov, Pakrashi, \& Oosterhof, 2009; Willis \& Todorov, 2006; Zebrowitz, Voinescu, \& Collins, 1996). Although these impressions of traits may not be accurate (Rule, Krendl, Ivcevic, \& Nalini, 2013), they are important because they frequently determine assessment of threat potential (Young, Slepian, \& Sacco, 2015) and influence approach or avoidance behaviours (Todorov, 2008). Moreover, the judgements of apparent traits affect social outcomes. For example, people invest more money with those who are perceived as more trustworthy in economic games (Ewing, Caulfield, Read, \& Rhodes, 2014; Rezlescu, Duchaine, Olivola, \& Chater, 2012; Stirrat \& Perrett, 2010). Judgements are made by individuals based on facial perceptions in mate preferences (Little, Burt, \& Perrett, 2006), electoral politics (Todorov, Mandisodza, Goren, \& Hall, 2005), hypothetical crime verdicts (Berry \& Zebrowitz-McArthur, 1988; Porter, ten Brinke, \& Gustaw, 2010; Shoemaker, South, \& Lowe, 1973) and even decisions about execution (condemning someone to death) (Wilson \& Rule, 2015).

In order to identify the dimensions on which individuals evaluate faces, Oosterhof \& Todorov (2008) conducted a principal component analysis on various trait adjectives inferred from neutral faces and reduced them to two main axes, trustworthiness and dominance. Oosterhof \& Todorov (2008) argued that the trustworthiness dimension signals an individual's harmful intent whereas the dominance dimension signals the capability to carry out the harmful intention. Hence, they suggested that these evaluations of trustworthiness and dominance are rooted in evolutionary mechanisms of threat detection. These and other studies suggest that the main attributions made to faces are trustworthiness and dominance (Oosterhof \& Todorov, 2008; Sutherland et al., 2013). 
Emotional expressivity plays an important role in perceptions of trustworthiness and dominance (Franklin \& Zebrowitz, 2013; Said, Sebe, \& Todorov, 2009; Sutherland et al., 2013). According to the emotion overgeneralisation hypothesis, trait judgement inferences rely on the resemblance of facial features to emotional expressions (Zebrowitz, 1996, 1997). That is, people make social judgements about neutral faces based on their similarities to emotional expressions. Under this hypothesis, trustworthiness is inferred from the similarity of features in neutral faces to emotionally positive expression traits (Franklin \& Zebrowitz, 2013; Sutherland et al., 2013). Studies have shown that neutral faces appearing to express slight happiness are perceived to be high in trustworthiness, whereas those appearing to express slight anger are perceived to be low in trustworthiness and high in dominance (Todorov \& Duchaine, 2008; Franklin \& Zebrowitz, 2013; Said et al., 2009). Using computergenerated images, researchers have found that exaggerating trustworthy facial features increases the likelihood that the face is classified as happy, whereas exaggerating untrustworthy features increases the classification of faces as angry (Oosterhof \& Todorov, 2008). In addition, Knutson (1996) proposed that happy, angry and disgusted faces involve high dominance and faces showing fear and sadness involve low dominance. Frijda (1986) found that pride, contempt and scorn are associated with the tendency for dominant behaviour, whereas humility, shame, guilt, remorse and devotion are associated with the tendency for submissive behaviour.

Neuroimaging studies have provided evidence that trustworthiness judgements are linked to emotional expressions and are associated with activation of brain areas, such as the amygdala, that generally process emotional information (Adolphs, 2002; Winston, Strange, O'Doherty, \& Dolan, 2002). Bilateral amygdala-damaged individuals are unable to make the judgements of trustworthiness typical of individuals without brain damage. Indeed amygdala damage can make faces that appear highly untrustworthy to control subjects look trustworthy (Adolphs, Tranel, \& Damasio, 1998). Individuals with bilateral amygdala damage also appear unable to discriminate emotional expressions of faces such as anger and happiness (Sato et al., 2002). Intriguingly, some studies find an inverse monotonic response: as the activity of the amygdala increases, perceptions of trustworthiness decrease (Engell, Haxby, \& Todorov, 2007), while other studies suggest a $\cup$-shaped, nonlinear trend with higher activation of the amygdala in response to faces at both extremes of the trustworthiness scale (Said, Baron, \& Todorov, 2009).

In addition, trustworthiness and dominance judgements of faces are associated with the structure of particular facial features, such as eyebrow ridge, cheek bones (Enlow \& Hans, 1996; Todorov, Baron, \& Oosterhof, 2008), distance between eyes and eyebrows (Oosterhof \& Todorov, 2008) and facial width (Stirrat \& Perrett, 2010; Weston, Friday, \& Liò, 2007). For example, Todorov et al. (2008) found that individuals with higher brow ridges, wider chins, noticeable cheek bones and a shallow nose sellion are perceived as more trustworthy than those with the opposite features. Face width-to-height ratio (fWHR: the bizygomatic separation scaled by the mid-face height from upper lip to eyebrow, Carré \& McCormick, 2008) has been reported to be linked to dominance (e.g., Haselhuhn \& Wong, 2012; Lewis, Lefevre, \& Bates, 2012; Stirrat \& Perrett, 2010). In addition, Stirrat \& Perrett (2010) found that trustworthiness inferences about men were predicted by fWHR, although Efferson \& Vogt (2013) found no correlation between the ratio and trustworthy behaviour. Furthermore, people may use facial structural cues such as forehead (tall/short), eyes (small/large) and face (heavy/light) to make social judgements about faces (Xu et al., 2012).

Both apparent emotional expression and apparent facial structure vary with head posture. For example, a down-tilted head indicates shame (Ekman \& Oster, 1979; Wiggers, 1982), sadness (Frijda, 1986) or embarrassment (Keltner \& Anderson, 2000) whereas an upwards head suggests joy and pride (Wallbott, 1998) or contempt (Rosenberg \& Ekman, 1995). 
Additionally, although they relate to anatomically stable dimensions, structural features of faces appear variable in two-dimensional images with changes in head tilt (Hehman, Leitner, \& Gaertner, 2013; Todorov, Olivola, Dotsch, \& Mende-Siedlecki, 2015). For example, a head-down posture seems to make the mouth appear more $U$-shaped than a head-level posture, whereas a head-up posture seems to make the mouth more $\cap$-shaped than a headlevel posture (Kappas, Hess, Barr, \& Kleck, 1994; Mignault \& Chaudhuri, 2003).

fWHR is affected by head posture, facial expression and photographic lens (Kramer, 2016). When individuals rotate their heads up and down, the perceived upper facial height will decrease while the perceived bizygomatic width remains the same, thus the perceived fWHR will be increased (Hehman et al., 2013, see Figure 1). Since rotating the head changes apparent emotional expressions and apparent face structure, both of which are important cues contributing to social attributions (Dzhelyova, Perrett, \& Jentzsch, 2012; Todorov et al., 2008), head rotation is likely to affect the perception of social traits.

We, therefore, were interested in how head posture (tilted upward, level and downward) affects perceptions of trustworthiness and dominance. We examined (a) whether perceptions of trustworthiness and dominance are linked to variation in posture and (b) whether any change in trustworthiness and dominance with posture arises from a change in facial emotional expressivity or fWHR. In our study, participants were asked to rate facial images in three postures for perceived trustworthiness, dominance and emotion on a seven point Likert scale to test whether head posture is associated with the perception of trustworthiness and dominance. We then analysed whether the changes in apparent emotion account for the change in perceived trustworthiness and dominance with head posture. We also calculated the fWHR and the shape of face features (mouth curvature and brow height) to test whether change in fWHR and or feature shape accounts for change in perceived trustworthiness and dominance with head posture.

\section{Methods}

This research was granted ethical approval by The School of Psychology \& Neuroscience Ethics Committee at the University of St Andrews (approval code: PS12103).

\subsection{Stimuli}

We took photographs of students (age 18-24, mean $=20.85, \mathrm{SD}=2.15$ years) from the University of St Andrews with a neutral expression, without decoration or make-up. Participants were asked to adopt three postures with their heads tilted upward, level and tilted downward. For an upward and downward posture, the researcher instructed them to raise or lower their heads, while fixating their eyes on the centre of the camera. Natural variation in posture between participants meant that the head-up rotation was $+30 \pm 5$ degrees, and the head rotation down was $-20 \pm 5$ degrees. Each image was delineated with 190 feature landmark points using Psychomorph (digital software for face processing, Tiddeman, Burt, \& Perrett 2001) and aligned via interpupillary distance (Rowland \& Perrett, 1995).

Composite stimuli of three faces were made by averaging the shape, colour and local texture of the three original faces together (Tiddeman et al., 2001) for each of the three different postures. Composites were constructed to create realistic facial images that were not recognisable as individuals. Composites therefore preserve anonymity of participants while appearing highly lifelike. A set of 72 images of 24 identities in three postures ( 12 of each sex) was thus available for the study. 


\section{2. fWHR and Face Measures}

We followed the methodology of Carré \& McCormick (2008) in calculating the fWHR of facial images with bizygomatic width (the maximum horizontal distance between the left and right zygion) divided by height (the distance between the midpoint along the Cupids bow of the upper lip and the lower surface at the middle of the eyebrows; see Figure 1).

Mouth curvature was measured following methods of Talamas et al. (2016) by taking the average height of the right and left corners of the mouth, subtracting the height of the centre of the mouth and dividing by the width of the mouth. Eyebrow height was measured as the vertical separation of the pupil centre and the centre of the lower margin of the brow. This measure was performed for the left and right brow and then the two values averaged.



Figure 1. Illustration of the measure of facial width-to-height ratio (fWHR) for three postures of the same composite face. White lines of box define the maximum horizontal distance between facial width and facial height. Both head-up and head-down postures increase apparent facial width-to-height ratio.

\subsection{Participants and Procedures}

A total of 71 American participants $(32$ females, 39 males, mean age $=37.0$, S.D. $=11.1$ years) was recruited with payment by Amazon Mechanical Turk. Participants completed three blocks of ratings: trustworthiness rating, dominance rating and emotion positivity rating, with blocks presented in random order. The data from four participants were rejected as they used the same rating for all or most judgements. The total set of 72 stimuli for rating included 24 identity images in three postures. Each rating block contained 24 trials (one third of the stimuli) with no face identity repeated, and was comprised of eight head-up, eight head-level and eight head-down postures. For a given rating task different thirds were randomly allocated to different participants. Thus for each rating task, each participant saw four males and four females each in one of three postures. Participants saw one chosen image displayed at a time, which could vary in posture: head-up, head-level or head-down. For trustworthiness and dominance ratings, participants were instructed "You will make judgements regarding trustworthiness (dominance). Please rate your impression from score 1 to 7 on how trustworthy (dominant) the face appears"; they then rated the stimuli for perceived trustworthiness (dominance) on a seven-point Likert scale (from 1 equalling very negative to 7 equalling very positive) with the question on the top of each facial image, "how trustworthy (dominant) does this face appear?". For emotion rating, participants were given the instructions "You will make judgements regarding the emotional expression. Please rate your impression of how positive the emotion expressed by the face is from score 1 to 7 ". Participants rated apparent emotional positivity with the endpoints of the seven-point scale labelled (1) very negative and (7) very positive.

\subsection{Analysis}


We used a repeated measures ANOVA with head posture as the independent variable (three levels: upward, level and downward) and dependent variable being ratings averaged across the faces tested in one posture. Hence, the 67 participants were the unit of analysis, with the participants' ratings averaged across the eight faces seen in one posture for one judgement. To study the role of emotional expression and face width in trait attributions we analysed the results using regression with expression or width as the predictor for trust or dominance ratings. For this analysis the 24 face stimuli were the unit of analysis and facial ratings were averaged across those participants that had rated each face stimulus.

To make direct comparisons between trait attributions, expression and facial width for each participant we computed the Pearson correlation between trait and emotion ratings for the 24 faces and the correlation between trait ratings and fWHR for the 24 faces. A paired samples t-test was then used to assess whether the correlation values between trait and expression were different from those between trait and fWHR across the participants. We compared absolute values of correlation coefficient to accommodate change in sign across the two correlations.

\section{Results}

\subsection{Trustworthiness}

We found a marked effect of changes in head posture on apparent trustworthiness $(\mathrm{F}(2$, $\left.132)=81.35, p<.001, \eta_{p}{ }^{2}=0.55\right)$. Paired samples t-tests showed that the head-level posture $(\mathrm{M}=4.41, \mathrm{SD}=0.70)$ was perceived to be more trustworthy compared to the head-down $(\mathrm{M}$ $=3.26, \mathrm{SD}=0.86, t=11.42, p<.001)$ and head-up posture $(\mathrm{M}=3.97, \mathrm{SD}=0.78, t=5.53$, $p<.001)$ postures. The head-down was perceived to be less trustworthy compared to the head-up $(t=-7.77, p<.001)$ (see Figure 2a).

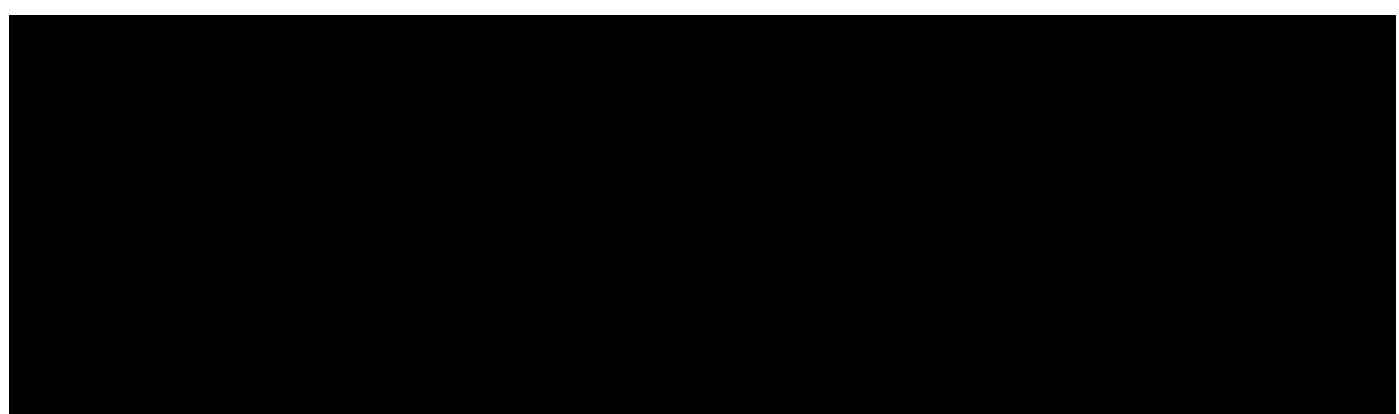

Figure 2. The effect of head posture on (a) trustworthiness, (b) submissiveness and (c) emotional positivity ratings. Average ratings on a seven-point Likert scale with standard error bars.

\subsection{Dominance/Submissiveness}

Dominance was reverse coded as submissiveness because submissiveness showed the same pattern of results as trustworthiness whereas dominance showed a reciprocal pattern. We found a marked effect of change in head posture on apparent submissiveness $(\mathrm{F}(2,132)$ $\left.=12.02, p<.001, \eta_{p}{ }^{2}=0.15\right)$. Paired samples t-tests showed that head-level posture $(\mathrm{M}=$ $4.11, \mathrm{SD}=0.65)$ was perceived to be more submissive compared to the head-down $(\mathrm{M}=3.61$, $\mathrm{SD}=0.86, t=4.38, p<.001)$ and head-up $(\mathrm{M}=3.68, \mathrm{SD}=0.78, t=4.69, p<.001)$ postures, while there was no significant difference between head-down and head-up postures $(t=-0.58$, $p=.563)$ (see Figure 2b).

\subsection{Emotion}


A comparable analysis showed that head posture affected ratings of emotional positivity $\left(\mathrm{F}(2,132)=63.50, p<.001, \eta_{p}^{2}=0.490\right)$. Paired samples $\mathrm{t}$-tests showed that head-level posture $(\mathrm{M}=3.91, \mathrm{SD}=0.55)$ was perceived to be more emotionally positive compared to the head-down posture $(\mathrm{M}=3.10, \mathrm{SD}=0.66, t=9.20, p<.001)$ and showed a trend to be more positive than head-up posture $(\mathrm{M}=3.78, \mathrm{SD}=0.60, t=1.94, p=.057)$. The head-down was perceived to be less emotionally positive compared to the head-up posture $(t=-9.20, p$ $<.001$ ) (see Figure 2c).

\subsection{Facial Width-To-Height Ratio}

Similar analysis confirmed that head posture affected fWHR $(\mathrm{F}(2,46)=61.67, p<.001$, $\left.\eta_{p}{ }^{2}=0.90\right)$. Paired samples t-tests showed that the fWHR for head-level posture $(\mathrm{M}=1.85$, $\mathrm{SD}=0.08)$ was lower than that for the head-down $(\mathrm{M}=1.92, \mathrm{SD}=0.10, t=5.44, p<.001)$ and the head-up $(\mathrm{M}=2.01, \mathrm{SD}=0.08, t=13.11, p<.001)$ postures. The fWHR for the headdown was lower than for the fWHR head-up posture $(t=-5.13, p<.001)$ (see Figure 3a).


Figure 3. The effect of head posture on facial width-to-height ratio, eyebrow height and mouth curvature. (a) Average facial width-to-height ratios (and standard errors) across 24 facial stimuli in three head postures. (b) Height (in pixels) of the eyebrows above the pupils, low values indicate lowered brow (apparent frowning). (c) Mouth curvature, positive values indicate an upturned mouth (apparent smiling).

\subsection{Expressive Facial Features}

Head posture affected the height of the eyebrows above the eyes $(\mathrm{F}(2,46)=99.31, p<$ $\left..001, \eta_{p}{ }^{2}=0.81\right)$. Paired samples t-tests showed that the brows for the head-up $(\mathrm{M}=35.09$, $\mathrm{SD}=4.81)$ posture were higher than for the head-level $(\mathrm{M}=30.80, \mathrm{SD}=5.45, t 23=6.54, p$ $<.001)$ and for the head-down $(\mathrm{M}=22.08, \mathrm{SD}=6.37, t 23=9.53, p<.001)$ postures. The brows for the head-up posture were higher than for the head-down posture $(t=11.04, p<$ .001 ) (see Figure 3b).

Head posture also affected the curvature of the mouth $\left(\mathrm{F}(2,46)=326.02, p<.001, \eta_{p}{ }^{2}=\right.$ $0.93)$. Paired samples t-tests showed that the mouth corners were more upturned in the headdown $(\mathrm{M}=5.25, \mathrm{SD}=2.47)$ posture, and were higher than for the head-level $(\mathrm{M}=-1.72, \mathrm{SD}$ $=2.58, t 23=15.08, p<.001)$ and for the head-up $(\mathrm{M}=8.41, \mathrm{SD}=2.01, t 23=22.59, p<$ $.001)$ postures. The mouth was more upturned for the head-level than for the head-up posture $(t=12.70, p<.001)$ (see Figure 3c).

\subsection{Traits and Emotion}

\subsubsection{Trustworthiness and emotion}

For each of the 24 face identities in each of the three postures, we averaged ratings across 
all participants for the same face and posture. We found a positive linear relationship between the average emotional positivity ratings and the average trustworthiness ratings across $\beta=$ participants for the 24 faces (head-down trustworthiness vs head-down emotional positivity: unstandardised $\mathrm{B}=0.86, \mathrm{SE}=0.14$, standardised $\beta=.79, t=6.07, p=.001, R^{2}=.63$; headlevel trustworthiness vs head-level emotional positivity: $\mathrm{B}=1.02, \mathrm{SE}=0.12, \beta=.88, t=$ $8.56, p<.001, R^{2}=.77$; head-up trustworthiness vs head-up emotional positivity: $\mathrm{B}=0.92$, $\mathrm{SE}=0.12, \beta=.85, t=7.57, p<.001, R^{2}=.72$; see Figure $4 \mathrm{a}, \mathrm{b}, \mathrm{c}$, respectively).

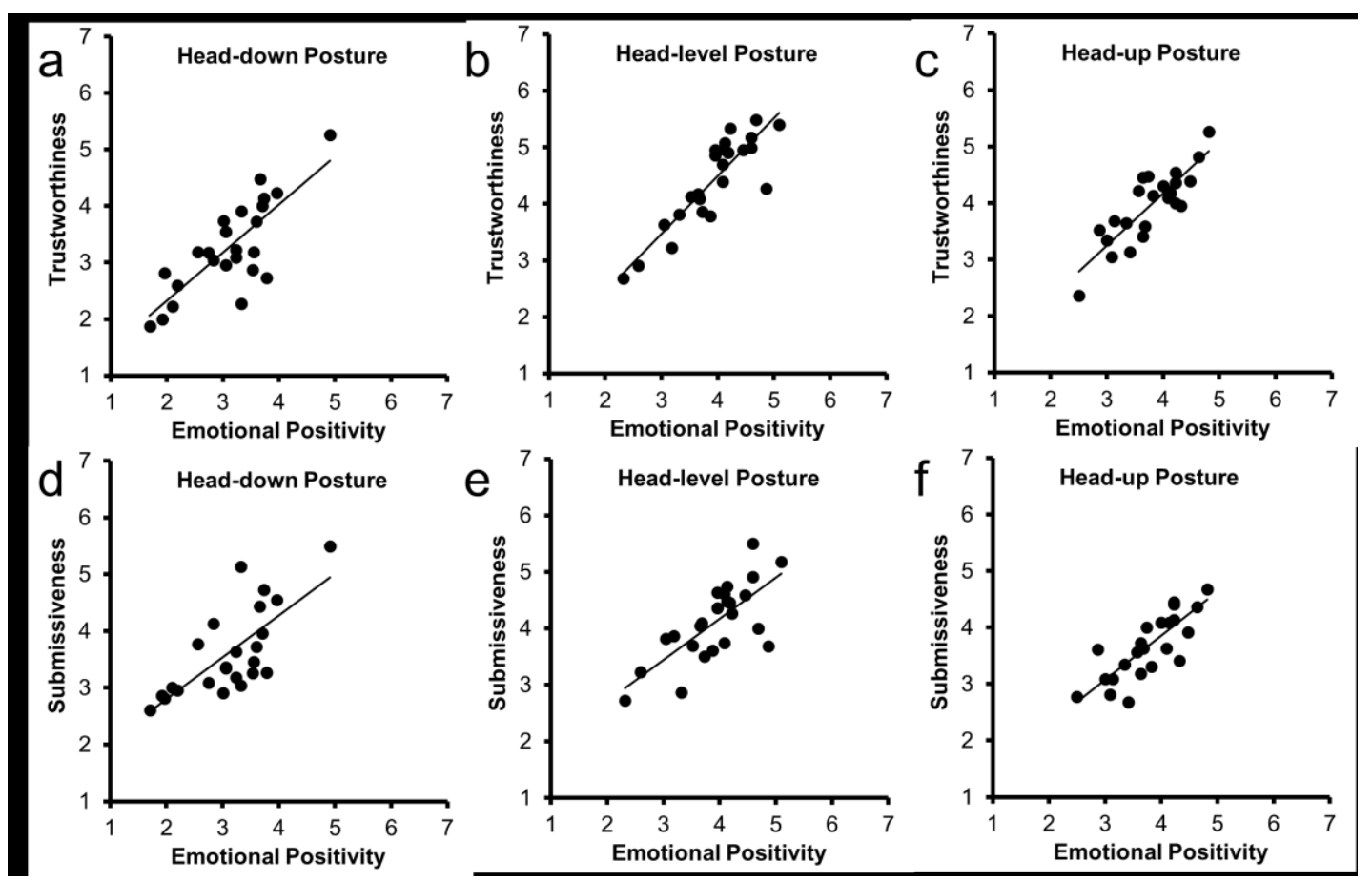

Figure 4. Relationship between ratings of apparent emotional positivity and trustworthiness (top row a-c) and submissiveness (bottom row d-f) for head-down, head-level and head-up postures. Each graph displays the perceptual ratings for 24 facial stimuli together with the best fit linear regression between ratings of emotional positivity and the trait.

In addition, the change in ratings of emotional positivity of the faces with posture change positively correlated with the change in ratings for the trustworthiness of the faces for the same posture change. Specifically, for the change in head-level to head-up posture, regression showed that the change in emotional positivity ratings across the 24 facial stimuli predicted the change in trustworthiness ratings $\left(\mathrm{B}=0.81, \mathrm{SE}=0.24, \beta=.59, t=3.40, p=.003, R^{2}\right.$ $=.35$, Figure 5a). Likewise, for the change in head-level to head-down posture, the change in emotional positivity ratings predicted the change in trustworthiness ratings $(\mathrm{B}=0.56, \mathrm{SE}=$ $0.19, \beta=.53, t=2.93, p=.008, R^{2}=.28$, Figure $5 \mathrm{~b}$ ).

\subsubsection{Submissiveness and emotion}

We found a positive linear relationship between the average emotional positivity ratings and the average submissiveness ratings across participants for the 24 faces (head-down submissiveness vs head-down emotional positivity: $\mathrm{B}=0.74, \mathrm{SE}=0.15, \beta=.73, t=4.93, p$ $<.001, R^{2}=.53$; head-level submissiveness vs head-level emotional positivity: $\mathrm{B}=0.73$, SE $=0.15, \beta=.73, t=4.98, p<.001, R^{2}=.51$; head-up submissiveness vs head-up emotional positivity: $\mathrm{B}=0.78, \mathrm{SE}=0.13, \beta=.80, t=4.93, p<.001, R^{2}=.64$; see Figure $4 \mathrm{~d}, \mathrm{e}, \mathrm{f}$ respectively 
In addition, the change in ratings of emotional positivity of the faces with posture change positively correlated with the change in ratings for the submissiveness of the faces for the same posture change. For the change in head-level to head-up posture, change in emotional positivity ratings predicted the change in submissiveness ratings $(\mathrm{B}=0.81, \mathrm{SE}=0.24, \beta=$ $.59, t=3.41, p=.003, R^{2}=.28$, Figure $5 \mathrm{c}$ ). Likewise, for the change in head-level to headdown posture the change in emotional positivity ratings predicted the change in submissiveness ratings $\left(\mathrm{B}=0.56, \mathrm{SE}=0.19, \beta=.53, t=2.93, p=.008, R^{2}=.35\right.$, Figure $\left.5 \mathrm{~d}\right)$.

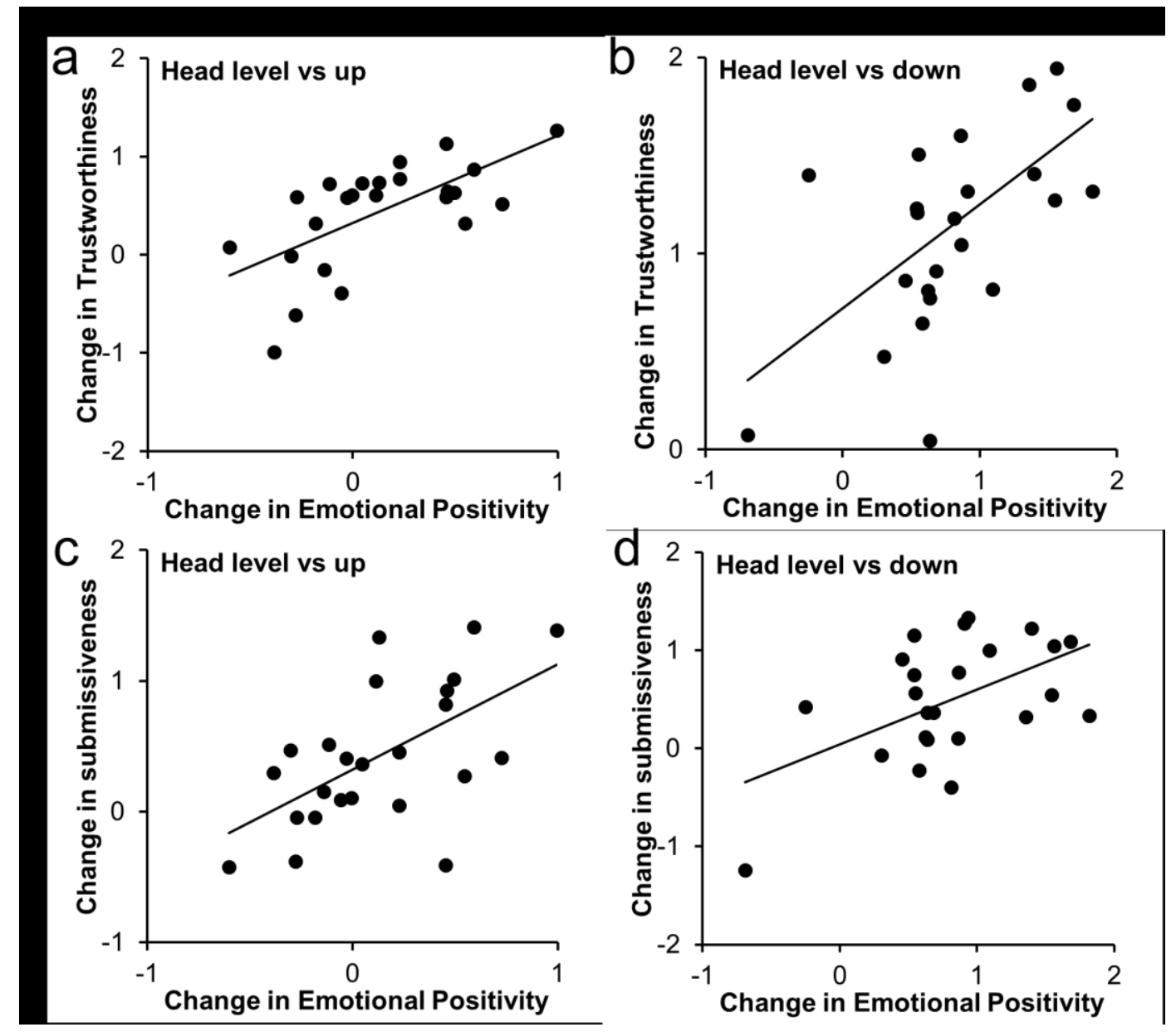

Figure 5. Relationship between change in apparent emotional positivity ratings and change in trustworthiness ratings (top row a-b) and change in submissiveness ratings (bottom row c-d) for changes in head posture from head-up to head-level posture (a, c) and from head-level to head-down postures $(b, d)$. Each graph displays the perceptual ratings for 24 facial stimuli together with the best fit linear regression between change in ratings of emotional positivity and the trait.

We might expect trustworthiness and submissiveness ratings to correlate because emotional positivity relates to both trust and submissiveness. Indeed there was a positive linear relationship between the average trust ratings and the average submissive ratings across participants for the 24 faces (head-up trustworthiness vs submissiveness: $\mathrm{B}=0.79, \mathrm{SE}=010$, $\beta=.87, t=8.36, p<.001, R^{2}=.75$; head-level trustworthiness vs submissiveness: $\mathrm{B}=0.68$, $\mathrm{SE}=0.11, \beta=.79, t=5.95, p<.001, R^{2}=.60$; head-down trustworthiness vs submissiveness: $\left.\mathrm{B}=0.79, \mathrm{SE}=0.11, \beta=.84, t=7.13, p=.001, R^{2}=.75\right)$.

\subsection{Traits and fWHR}

\subsubsection{Trustworthiness and fWHR}


We compared the average trustworthiness ratings for the 24 faces in each posture with fWHR measures of the faces in the equivalent posture. The trustworthiness and fWHR measures were unrelated in each posture (head-up trustworthiness vs fWHR: $\mathrm{B}=-2.55 \mathrm{SE}=$ $1.54, \beta=-0.33, t=-1.66, p=.11, R^{2}=.11$; head-level trustworthiness vs fWHR: $\mathrm{B}=-0.52$, $\mathrm{SE}=2.19, \beta=-0.50, t=-0.24, p=.82, R^{2}=.003$; head-down trustworthiness vs $\mathrm{fWHR}: \mathrm{B}=$ $1.06, \mathrm{SE}=1.76, \beta=.13, t=0.60, p=.55, R^{2}=.02$ ).

When a head changes from the head-level posture to head-up or head-down postures, the facial width-to-height ratio changes (as documented in Figures 1 and 3) in addition to the apparent emotional positivity. The amount that fWHR changes will differ across the 24 faces and two directions of posture change. If the change in fWHR drives the change in trait perception, then fWHR change should be a significant predictor of trait judgement change in regression analysis. Against this prediction, there was no relationship between changes in fWHR and changes in trustworthiness ratings across posture change. Specifically, change in fWHR (head-level vs head-up or head-level vs head-down) was not related to change in rating of trustworthiness (head-level to head-up $\mathrm{B}=1.87, \mathrm{SE}=1.91, \beta=.21, t=0.98, p=.34, R^{2}=$ .07 ; head-level to head-down $\mathrm{B}=-1.63, \mathrm{SE}=1.84, \beta=-0.19, t=-0.89, p=.39, R^{2}=.03$ ). If apparent facial width underlies apparent trustworthiness, fWHR changes should mirror changes in the trustworthiness ratings yet the results show otherwise.

\subsubsection{Submissiveness and fWHR}

We compared the average submissiveness ratings for the 24 faces in each posture with fWHR measures of the faces in the equivalent posture. The submissiveness and fWHR measures were unrelated in each posture (head-up submissiveness vs head-up fWHR: $\mathrm{B}=$ $2.40, \mathrm{SE}=1.39, \beta=-0.35, t=-1.73, p=.10, R^{2}=.12$; head-level submissiveness vs headlevel fWHR: $\mathrm{B}=-2.00, \mathrm{SE}=1.84, \beta=-0.22, t=-1.07, p=.29, R^{2}=.05$; head-down submissiveness vs head-down fWHR: $\mathrm{B}=-0.41, \mathrm{SE}=1.69, \beta=-0.05, t=-0.25, p=.81, R^{2}$ $<.01)$.

In addition, we found no relation between changes in fWHR and changes in submissiveness ratings. Specifically, change in fWHR (head-level vs head-up or head-level vs head-down) was not found to relate to change in rating of submissiveness (head-level vs head-up or head-level vs head-down) across the different faces (head-level to head-up: $\mathrm{B}=$ $0.073, \mathrm{SE}=1.39, \beta=.01, t=0.05, p=.96, R^{2}<.01$; head-level to head-down: $\mathrm{B}=-1.22, \mathrm{SE}$ $=1.30, \beta=-0.20, t=-0,93, p=.36, R^{2}=.11$ ). If facial width accounts for apparent submissiveness, fWHR changes should mirror changes in the submissiveness ratings but again the results suggest otherwise.

\subsection{Contrasting Emotion and Facial Width as Trait Predictors}

\subsubsection{Trustworthiness: emotion vs facial width}

To determine more directly whether the strength of the relationship between trustworthiness and emotional positivity differed from that related to fWHR we computed correlations for each participant. The average Pearson correlation coefficient between trustworthiness and emotional positivity for each of the 67 participants was $\mathrm{M}=0.53, \mathrm{SD}=$ 0.19 whereas the average correlation between trustworthiness and fWHR was $\mathrm{M}=-0.07, \mathrm{SD}$ 0.20 . The correlation with emotional positivity was significantly larger than that with facial width (paired samples- $t$ test of absolute values of correlations across participants, $t 66=13.86$, $p<.001)$. Comparisons revealed similar differences in each of the three head postures. The average correlation between trustworthiness and emotional positivity in head-up, head-level and head-down postures were $\mathrm{M}=0.49, \mathrm{SD}=0.29 ; \mathrm{M}=0.42, \mathrm{SD}=0.33, \mathrm{M}=0.52, \mathrm{SD}=$ 0.27 , respectively, whereas the average correlations between trustworthiness and fWHR in the same three postures were $\mathrm{M}=-0.20, \mathrm{SD}=0.29 ; \mathrm{M}=0.01, \mathrm{SD}=0.30, \mathrm{M}=0.11, \mathrm{SD}=$ 
0.32 respectively. For each head posture the absolute value of correlation with emotional positivity was significantly larger than that with facial width (each comparison: $t>5.98, p<$ $0.001)$.

\subsubsection{Submissiveness: emotion vs facial width}

To compare the strength of the relationship between submissiveness and emotional positivity with that related to fWHR we computed correlations for each participant. The average correlation between submissiveness and emotional positivity for each of the 67 participants was $\mathrm{M}=0.30, \mathrm{SD}=0.26$, whereas the average correlation between submissiveness and fWHR was $\mathrm{M}=0.15, \mathrm{SD}=0.19$. The absolute value of the correlation between submissiveness and emotional positivity was significantly larger than that with facial width $(t 66=4.91, p<0.001)$. Comparisons revealed similar differences in each of the three head postures. The average correlation between submissiveness and emotional positivity in head-up, head-level, and head-down postures was $\mathrm{M}=0.35, \mathrm{SD}=0.31 ; \mathrm{M}=0.26, \mathrm{SD}=0.41$; $\mathrm{M}=0.33, \mathrm{SD}=0.39$, respectively; whereas the average correlation between submissiveness and fWHR in the same three postures was $\mathrm{M}=-0.18, \mathrm{SD}=0.32 ; \mathrm{M}=-0.15, \mathrm{SD}=0.35 ; \mathrm{M}=$ $0.02, \mathrm{SD}=0.33$, respectively. For each head posture the absolute value of correlation with emotional positivity was significantly larger than that with facial width (each comparison: $t$ $>=2.07, p<=.04)$.

\subsection{Traits and Expressive Facial Features}

\subsubsection{Trustworthiness and expressive facial features}

We used multiple linear regression to compare the average trustworthiness ratings for the 24 faces in each posture with face shape measures in the equivalent posture. Trustworthiness was predicted by upward mouth curvature and increased eyebrow height in each posture (head-up: brow height, $\mathrm{B}=0.08, \mathrm{SE}=0.02, \beta=.62, t=4.12, p<.001$, mouth curvature, $\mathrm{B}=$ $0.10, \mathrm{SE}=0.05, \beta=.32, t=2.11, p=.047$, overall model, $R^{2}=.52$; head-level: brow height, $\mathrm{B}=0.07, \mathrm{SE}=0.02, \beta=.49, t=3.42, p=.003$, mouth curvature, $\mathrm{B}=0.21, \mathrm{SE}=0.04, \beta=$ $.67, t=4.70, p<.001$, overall model, $R^{2}=.58$; head-down: brow height, $\mathrm{B}=0.05, \mathrm{SE}=0.02$, $\beta=.38, t=2.09, p=.049$, mouth curvature: $\mathrm{B}=0.16, \mathrm{SE}=0.06, \beta=.49, t=2.74, p=.012$, overall model, $R^{2}=.33$ ).

In addition the changes in feature shape with posture change tended to be related to the change in trustworthiness ratings for the posture change from head-level to head-down (brow height, $\mathrm{B}=0.06, \mathrm{SE}=0.03, \beta=.50, t=1.96, p=.063$, mouth curvature, $\mathrm{B}=0.13, \mathrm{SE}=0.06$, $\beta=.56, t=2.21, p=.038$, overall model $R^{2}=.21$ ). The relationship between feature shape and trustworthiness was not evident for the posture change between head-level and head-up (brow height, $p=.638$, mouth curvature, $p=.105$, overall model, $R^{2}=.22$ ). Overall these analyses show that increased trustworthiness judgements were related to raised eyebrows and an up-turned mouth curvature.

\subsubsection{Submissiveness and expressive facial features}

We used multiple linear regression to compare the average submissiveness ratings for the 24 faces in each posture with face shape measures in the equivalent posture. Submissiveness was predicted by upward mouth curvature and/or increased eyebrow height in each posture (head-up: brow height, $\mathrm{B}=0.07, \mathrm{SE}=0.02, \beta=.55, t=3.27, p=.004$, mouth curvature, $\mathrm{B}=$ $0.08, \mathrm{SE}=0.05, \beta=.27, t=1.50, p=.132$, overall model, $R^{2}=.41$; head-level: brow height, $\mathrm{B}=0.09, \mathrm{SE}=0.02, \beta=.70, t=5.39, p<.001$, mouth curvature, $\mathrm{B}=0.15, \mathrm{SE}=0.03, \beta=$ $.55, t=4.24, p<.001$, overall model, $R^{2}=.66$; head-down: brow height, $\mathrm{B}=0.07, \mathrm{SE}=0.2$, $\beta=.54, t=3.25, p=.004$, mouth curvature: $\mathrm{B}=0.14, \mathrm{SE}=0.05, \beta=.44, t=2.63, p=.016$, 
overall model, $R^{2}=.42$ ).

The change in submissiveness ratings for the posture change from head-level to head-down was related to the change in brow height $(\mathrm{B}=0.08, \mathrm{SE}=0.04, \beta=.55, t=2.12, p=.046)$ but not to the change in mouth curvature $\left(p=.595\right.$, overall model $\left.R^{2}=.18\right)$. The relationship between feature shape and submissiveness was not evident for the posture change between head-level and head-up postures (brow height, $p=.681$, mouth curvature, $p=.933$, overall model, $R^{2}=.01$ ). These analyses show that, like trust judgements, increased submissiveness judgements were related to raised eyebrows and up-turned mouth curvature.

\section{Discussion}

In this paper, we explored how head posture affects social perceptions. Our findings provide more evidence regarding the association between emotional expressions and judgements of trustworthiness and dominance. We find that facial features associated with positive affect (i.e. an upturned mouth shape and raised eyebrows) are associated with increased trustworthiness and decreased dominance (increased submissiveness). In contrast, we find no evidence that trait impressions due to head posture are explained by facial width.

As expected, we found a significant effect of posture on apparent trustworthiness and dominance. First, results of ratings reveal that a head-down posture (rotated 25 degrees down) decreased perceived trustworthiness and submissiveness compared to the head-level; the head-up posture was also perceived as less trustworthy and less submissive compared to the neutral head-level posture. These findings align with studies which indicate that both a downwards head tilt and upwards head tilt increased perceptions of dominance and various other antisocial (and non-warm) personality traits likely related to trustworthiness (e.g., intimidation, physical strength; Hehman et al., 2013; Toscano, Schubert, \& Giessner, 2018), compared to a resting (neutral) head angle. These results contradict the findings of previous studies which associate a raised head with dominance posture and a bowed head with submissiveness posture (Mignault \& Chaudhuri 2003; Tracy \& Matsumoto 2008). Gaze direction may offer an explanation for the discrepancy (see Toscano et al., 2018). In our stimuli, gaze was always directed at the camera and observer. The head-down posture with direct gaze is likely to be seen as threatening and indicative of an intention to attack (Horstmann \& Ansorge, 2011). As a result, the threat of a downward tilted face might be perceived as more dominant compared to individuals with a head-level posture. In previous studies the gaze was either not visible (Mignault \& Chaudhuri, 2003) or likely to have been directed downward in displays of shame (Tracy \& Matsumoto, 2008).

We also found that apparent emotional positivity contributes to the explanation of the variation in both trust and dominance judgements. Emotional positivity can thus predict the impact of posture on the perception of trustworthiness and dominance. These findings align with studies which indicate the contribution of emotional expressions to perceptions of social judgements (Franklin \& Zebrowitz, 2013; Lyons et al. 2000; Said et al., 2009; Sutherland et al. 2013; Witkower \& Tracy 2018). The effect sizes relating emotional positivity to trait attributes were moderate in magnitude (i.e. between 0.3 and 0.7 ) when analysed at the level of each participant (Brand \& Bradley 2012).

Previous studies investigated the relationship between trait perception and facial width (e.g., Geniole, Molnar, Carré, \& McCormick, 2014; Stirrat \& Perrett, 2010; Tognetti, Berticat, Raymond, \& Faurie, 2013). We attempted to replicate this previous research by exploring the influence of head posture on apparent fWHR and the traits of trustworthiness and dominance. Our results show that there is no relation between change in apparent fWHR and change in the perception of trustworthiness or dominance. Judgements of both trustworthiness and dominance therefore may rely more on apparent emotion than apparent 
facial width.

Principle components analysis (PCA) studies of facial attributions separate trustworthiness and dominance dimensions (Oosterhof \& Todorov, 2008; Sutherland et al., 2013) yet here the two attributions show moderate positive correlation. An explanation for the unanticipated correlation of trust and dominance ratings in our study is that we introduced a large degree of head tilt as a new variable. This variable may cause ratings to be correlated because tilt changes both apparent emotion and masculinity. A head tilted downward 25 degrees may make the face appear more emotionally negative and more masculine than a head-level posture. Hence this posture is likely to lower trustworthy scores and lower submissiveness scores - introducing a positive correlation between trustworthiness and submissiveness. How head tilt over large angles changes masculinity attributions needs further study (Burke \& Sulikowski, 2010).

Human vision fails to recover the full three-dimensional structure of the face. For example, when the head is rotated down, observers may misinterpret the mouth curvature as consistent with a slight smile but the lowering of the eyebrows as anger. Obviously, in reality there is no change in the emotional expression as the head is tilted yet the change in apparent expression is compelling. The same misperception occurs for apparent three-dimensional structure; lowering the head makes the chin and forehead look slightly smaller (see Figure 1). Indeed, the changes to the apparent structure present a further alternative explanation for the effects of posture on trustworthiness and dominance. Vertical rotation of the head in one direction creates facial feature changes associated with both positive and negative affect. For example, Figure 3 shows that head rotation up raises eyebrow height which is associated with positive emotion but also makes the mouth curve down which is associated with negative emotion. We measured two cues but there are likely to be more. From the present study it appears that cues to negative affect take priority over cues to positive affect if both change. The nature of other facial cues and the balance given to them in trait judgements needs further investigation.

In conclusion, we have found a profound effect of posture on apparent trustworthiness and dominance: compared to the neutral head-level posture, a posture rotated 25 degrees down markedly decreased perceived trustworthiness and submissiveness as did a posture rotated 30 degrees up. Together with evidence of previous research, our study highlights the function of head posture in cueing personality and signalling social traits. Emotional positivity was found to explain the effects of posture on trustworthiness and dominance judgements whereas there was no correlation between perceived fWHR and trustworthiness. Thus our analysis reveals that trustworthiness and dominance are closely aligned with apparent emotional expression.

\section{Funding}

This research was supported by grants from the National Natural Science Foundation of China (No. 61602079; No.61632011) and the Humanity and Social Science Youth Foundation of Ministry of Education of China (No. 16YJCZH141).

\section{References}

Adolphs, R. (2002). Trust in the brain. Nature Neuroscience, 5 (3): 192-193. https://doi.org/10.1038/nn0302-192

Adolphs, R., Tranel, D., \& Damasio, A. R. (1998). The human amygdala in social judgment. Nature, 393 (6684), 470-474. https://doi.org/10.1038/30982

Berry, D. S., \& Zebrowitz-McArthur, L. (1988). What's in a face? Facial maturity and the attribution of 
legal responsibility. Personality and Social Psychology Bulletin, 14 (1), 23-33. https://doi.org/10.1177/0146167288141003

Brand, A., \& Bradley, M. T. (2012). More voodoo correlations: When average-based measures inflate correlations. The Journal of General Psychology, 139 (4), 260-272. https://doi.org/10.1080/00221309.2012.703711

Burke, D., \& Sulikowski, D. (2010). A new viewpoint on the evolution of sexually dimorphic human faces. Evolutionary Psychology, 8 (4), 573-585. https://doi.org/10.1177/147470491000800404

Carré, J. M., \& McCormick, C. M. (2008). In your face: facial metrics predict aggressive behaviour in the laboratory and in varsity and professional hockey players. Proceedings of the Royal Society of London B: Biological Sciences, 275 (1651): 2651-2656. https://doi.org/10.1098/rspb.2008.0873

Dzhelyova, M., Perrett, D. I., \& Jentzsch, I. (2012). Temporal dynamics of trustworthiness perception. Brain Research, 1435 (2), 81-90. https://doi.org/10.1016/j.brainres.2011.11.043

Efferson, C., \& Vogt, S. (2013). Viewing men's faces does not lead to accurate predictions of trustworthiness. Scientific Reports, 3 (4), 1047. https://doi.org/10.1038/srep01047

Ekman, P., \& Oster, H. (1979). Facial expressions of emotion. Annual Reviews of Psychology, 30 (1), $527-$ 554. https://doi.org/10.1146/annurev.ps.30.020179.002523

Engell, A. D., Haxby, J. V. \& Todorov, A. (2007). Implicit trustworthiness decisions: automatic coding of face properties in the human amygdala. Journal of Cognitive Neuroscience, 19 (9),1508-1519. https://doi.org/10.1162/jocn.2007.19.9.1508

Enlow, D. H., \& Hans, M. G. (1996). Essentials of Facial Growth. Philadelphia, PA, Saunders. https://doi.org/10.1016/S0278-2391(97)90621-2

Ewing, L., Caulfield, F., Read, A., \& Rhodes, G. (2014). Perceived trustworthiness of faces drives trust behaviour in children. Developmental Science, 18 (2), 327-334. https://doi.org/10.1111/desc.12218

Franklin, R., \& Zebrowitz, L. A. (2013). Older adults' trait impressions of faces are sensitive to subtle resemblance to emotions. Journal of Nonverbal Behavior, 37 (3), 139-151. https://doi.org/10.1007/s10919-013-0150-4

Frijda, N. H. (1986). The Emotions. Cambridge, UK: Cambridge University Press.

Geniole, S. N., Molnar, D. S., Carré, J. M., \& McCormick, C. M. (2014). The facial width-to-height ratio shares stronger links with judgments of aggression than with judgments of trustworthiness. Journal of Experimental Psychology: Human Perception and Performance, 40 (4), 1526-1541. https://doi.org/10.1037/a0036732

Haselhuhn, M. P., \& Wong, E. M. (2012). Bad to the bone: facial structure predicts unethical behaviour. Proceedings of the Royal Society B-Biological Sciences, 279 (1728), 571-576. https://doi.org/10.1098/rspb.2011.1193

Hehman, E., Leitner, J. B., \& Gaertner, S. L. (2013). Enhancing static facial features increases intimidation. Journal of Experimental Social Psychology, 49 (4), 747-754. https://doi.org/10.1016/j.jesp.2013.02.015

Horstmann, G., \& Ansorge, U. (2011) Compatibility between tones, head movements, and facial expressions. Emotion, 11 (4), 975-980. https://doi.org/10.1037/a0023468

Kappas, A., Hess, U., Barr, C. L., \& Kleck, R. E. (1994). Angle of regard: The effect of vertical viewing angle on the perception of facial expressions. Journal of Nonverbal Behavior, 18 (4), 263-280. https://doi.org/10.1007/BF02172289

Keltner, D., \& Anderson, C. (2000). Saving face for Darwin: The functions and uses of embarrassment. Current Directions in Psychological Science, 9 (6), 187-192. https://doi.org/10.1111/14678721.00091

Knudson, B. (1996). Facial expressions of emotion influence interpersonal trait inferences. Journal of Nonverbal Behavior, 20 (3) 165-182. https://doi.org/10.1007/BF02281954

Kramer, R. S. (2016). Within-person variability in men's facial width-to-height ratio. PeerJ, 4: e1801. https://doi.org/10.7717/peerj.1801

Krumhuber, E., Manstead, A. S., Cosker, D., Marshall, D., Rosin, P. L., \& Kappas, A. (2007). Facial dynamics as indicators of trustworthiness and cooperative behavior. Emotion, 7 (4), 730-735. https://doi.org/10.1037/1528-3542.7.4.730

Lewis, G. J., Lefevre, C. E., \& Bates, T. C. (2012). Facial width-to-height ratio predicts achievement drive in US presidents. Personality and Individual Differences, 52 (7), 855-857. https://doi.org/10.1016/j.paid.2011.12.030

Little, A. C., Burt, D. M., \& Perrett, D. I. (2006). What is good is beautiful: Face preference reflects desired personality. Personality and Individual Differences, 41 (6): 1107-1118. 
https://doi.org/10.1016/j.paid.2006.04.015

Lyons, M. J., Campbell, R., Plante, A., Coleman, M., Kamachi, M., \& Akamatsu, S. (2000). The Noh mask effect: Vertical viewpoint dependence of facial expression perception. Proceedings of the Royal Society of London. Series B: Biological Sciences, 267 (1459), 2239-2245. https://doi.org/10.1098/rspb.2000.1274

Mignault, A., \& Chaudhuri, A. (2003). The many faces of a neutral face: Head tilt and perception of dominance and emotion. Journal of Nonverbal Behaviour, 27 (2), 111-132. https://doi.org/10.1023/A:1023914509763

Oosterhof, N. N., \& Todorov, A. (2008). The functional basis of face evaluation. Proceedings of the National Academy of Sciences of the USA, 105 (32), 11087-11092. https://doi.org/10.1073/pnas.0805664105

Porter, S., ten Brinke, L., \& Gustaw, C. (2010). Dangerous decisions: The impact of first impressions of trustworthiness on the evaluation of legal evidence and defendant culpability. Psychology, Crime \& Law, 16 (6), 477-491. https://doi.org/10.1080/10683160902926141

Rezlescu, C., Duchaine, B., Olivola, C. Y., \& Chater, N. (2012). Unfakeable facial configurations affect strategic choices in trust games with or without information about past behavior. PloS One, 7 (3): e34293. https://doi.org/10.1371/journal.pone.0034293

Rosenberg, E. L., \& Ekman, P. (1995). Conceptual and methodological issues in the judgment of facial expressions of emotion. Motivation and Emotion, 19 (2), 111-138. https://doi.org/10.1007/BF02250566

Rowland, D. A., \& Perrett, D. I. (1995). Manipulating facial appearance through shape and color. IEEE Computer Graphics and Applications, 15 (5), 70-76. https://doi.org/10.1109/38.403830

Rule, N. O., Krendl, A. C., Ivcevic, Z., \& Ambady, N. (2013). Accuracy and consensus in judgments of trustworthiness from faces: Behavioral and neural correlates. Journal of Personality and Social Psychology, 104 (3), 409-426. https://doi.org/10.1037/a0031050

Said, C. P., Baron, S. G., \& Todorov, A. (2009). Nonlinear amygdala response to face trustworthiness: contributions of high and low spatial frequency information. Journal of Cognitive Neuroscience, 21 (3), 519-28. https://doi.org/10.1162/jocn.2009.21041

Said, C. P., Sebe, N., \& Todorov, A. (2009). Structural resemblance to emotional expressions predicts evaluation of emotionally neutral faces. Emotion, 9 (2), 260-264. https://doi.org/10.1037/a0014681

Sato, W., Kubota, Y., Okada, T., Murai, T., Yoshikawa, S., Sengoku, A. (2002). Seeing happy emotion in fearful and angry faces: qualitative analysis of facial expression recognition in a bilateral amygdaladamaged patient. Cortex, 38 (5), 727-742. https://doi.org/10.1016/S0010-9452(08)70040-6

Shoemaker, D. J., South, D. R., \& Lowe, J. (1973). Facial stereotypes of deviants and judgments of guilt or innocence. Social Forces, 51 (4), 427-433. https://doi.org/10.2307/2576687

Stirrat, M., \& Perrett, D. I. (2010). Valid facial cues to cooperation and trust: Male facial width and trustworthiness. Psychological Science, 21 (3), 349-354. https://doi.org/10.1177/0956797610362647

Sutherland, C., Oldmeadow, J., Santos, I., Towler, J., Burt, D., \& Young, A. (2013). Social inferences from faces: Ambient images generate a three-dimensional model. Cognition, 127 (1), 105-118. https://doi.org/10.1016/j.cognition.2012.12.001

Talamas, S. N., Mavor, K. I., Axelsson, J., Sundelin, T., \& Perrett, D. I. (2016). Eyelid-openness and mouth curvature influence perceived intelligence beyond attractiveness. Journal of Experimental Psychology: General, 145 (5), 603-620. https://doi.org/10.1037/xge0000152

Tiddeman, B. P, Burt, D. M., \& Perrett, D. I. (2001). Prototyping and transforming facial textures for perception research. IEEE Computer Graphics and Applications, 21 (5), $42-50$. https://doi.org/10.1109/38.946630

Todorov, A. (2008). Evaluating faces on trustworthiness. Annals of the New York Academy of Sciences, 1124 (1), 208-224. https://doi.org/10.1196/annals.1440.012

Todorov, A., Baron, S. G., \& Oosterhof, N. N. (2008). Evaluating face trustworthiness: a model based approach. Social Cognition and Affective Neuroscience, 3 (2), 119-127. https://doi.org/10.1093/scan/nsn009

Todorov, A., \& Duchaine, B. (2008). Reading trustworthiness in faces without recognizing faces. Cognitive Neuropsychology, 25 (3), 395-410. https://doi.org/10.1080/02643290802044996

Todorov, A., Mandisodza, A., Goren, A., \& Hall, C. (2005). Inferences of competence from faces predict election outcomes. Science, 308 (5728), 1623-1626. https://doi.org/10.1126/science.1110589

Todorov, A., Olivola, C. Y., Dotsch, R., \& Mende-Siedlecki, P. (2015). Social attributions from faces: Determinants, consequences, accuracy, and functional significance. Annual Review of Psychology, 66 (1), 519-545. https://doi.org/10.1146/annurev-psych-113011-143831 
Todorov, A., Pakrashi, M., \& Oosterhof, N. N. (2009). Evaluating faces on trustworthiness after minimal time exposure. Social Cognition, 27 (6), 813-833. http://dx.doi.org/10.1521/soco.2009.27.6.813

Tognetti, A., Berticat, C., Raymond, M., \& Faurie, C. (2013). Is cooperativeness readable in static facial features? An inter-cultural approach. Evolution and Human Behavior, 34 (6), 427-432. http://dx.doi.org/10.1016/j.evolhumbehav.2013.08.002

Toscano, H., Schubert, T. W., \& Giessner, S. R. (2018). Eye gaze and head posture jointly influence judgments of dominance, physical strength, and anger. Journal of Nonverbal Behavior, 42 (3), 285-309. http://dx.doi.org/10.1007/s10919-018-0276-5

Tracy, J., \& Matsumoto, D. (2008). The spontaneous expression of pride and shame: Evidence for biologically innate nonverbal displays. Proceedings of the National Academy of Sciences, 105 (33), 11655-11660. https://doi.org/10.1073/pnas.0802686105

Wallbott, H. G. (1998). Bodily expression of emotion. European Journal of Social Psychology, 28 (6), 879896. https://doi.org/10.1002/(SICI)1099-0992(1998110)28:6<879::AID-EJSP901>3.0.CO;2-W

Weston, E. M., Friday, A. E., \& Liò, P. (2007). Biometric evidence that sexual selection has shaped the hominin face. PLoS One, 2 (8), e 710. https://doi.org/10.1371/journal.pone.0000710

Wiggers, M. (1982). Judgments of facial expressions of emotion predicted from facial behavior. Journal of Nonverbal Behavior, 7 (2), 101-116. https://doi.org/10.1007/BF00986872

Willis, J., \& Todorov, A. (2006). First impressions: Making up your mind after $100 \mathrm{~ms}$ exposure to a face. Psychological Science, 17 (7), 592-598. https://doi.org/10.1111/j.1467-9280.2006.01750.x

Wilson, J. P., \& Rule, N. O. (2015). Facial trustworthiness predicts extreme criminal-sentencing outcomes. Psychological Science, 26 (8), 1325-1331. https://doi.org/10.1177/0956797615590992

Winston, J. S., Strange, B. A., O’Doherty, J. \& Dolan, R. J. (2002). Automatic and intentional brain responses during evaluation of trustworthiness of faces. Nature Neuroscience, 5 (3), 277-283. http://dx.doi.org/10.1038/nn816

Witkower, Z., \& Tracy, J. L. (2018). Bodily communication of emotion: evidence for extrafacial behavioral expressions and available coding systems. Emotion Review, 11 (2), 184-193. https://doi.org/10.1177/1754073917749880

Xu, F., Wu, D., Toriyama, R., Ma, F., Itakura, S., \& Lee, K. (2012). Similarities and differences in Chinese and Caucasian adults' use of facial cues for trustworthiness judgments. PloS One, 7 (4), e34859. https://doi.org/10.1371/journal.pone.0034859

Young, S. G., Slepian, M. L., \& Sacco, D. F. (2015). Sensitivity to perceived facial trustworthiness is increased by activating self-protection motives. Social Psychological and Personality Science, 6 (6), 607-613. https://doi.org/10.1177/1948550615573329

Zebrowitz, L. A. (1996). Physical appearance as a basis for stereotyping. (pp. 79-120) In Macrae, C. N., Stangor, C., \& Hewstone, M. (Eds.) Stereotypes and Stereotyping. New York, NY: Guildford Press.

Zebrowitz, L. A. (1997). Reading faces: Window to the soul? Boulder, Colorado, Westview Press.

Zebrowitz, L. A., Voinescu, L., \& Collins, M. A. (1996). "Wide-eyed" and "crooked-faced": Determinants of perceived and real honesty across the life span. Personality and Social Psychology Bulletin, 22 (12), 1258-1269. https://doi.org/10.1177/01461672962212006 